\section{O trabalho dos pediatras em um serviço público de urgências: fatores intervenientes no atendimento}

\author{
Pediatric practice in public emergency services and \\ factors affecting care
}

\author{
${ }^{1}$ Faculdade de Medicina, \\ Universidade Federal de \\ Minas Gerais, Belo Horizonte, \\ Brasil. \\ Correspondência \\ E. M. C. Melo \\ Departamento de Pediatria, \\ Faculdade de Medicina, \\ Universidade Federal de \\ Minas Gerais. \\ Av. Alfredo Balena 190, $4 \underline{o}$ \\ andar, Belo Horizonte, $M G$ \\ 30310-100, Brasil. \\ egleamelo@uol.com.br
}

\begin{abstract}
This qualitative empirical study discusses the material and organizational conditions of work by pediatricians in a public emergency service, with the aim of identifying factors that affect care. The work was studied using group interviews and direct observation in the emergency unit. The results were compared with statistical and historical data from documental research. Forty-four pediatricians from seven teams were interviewed, and seven of the pediatricians were observed while on duty. The precarious referral and counter-referral system was a determinant factor leading to the heavy demand on the emergency unit. Agglomeration of patients and families at the entrance to the emergency service led to time pressure and interfered directly in the pediatric care. The study identified informal strategies devised and implemented by these physicians in attempts to guarantee the quality of care in keeping with pediatric principles.
\end{abstract}

Emergency Medical Services; Health Services; Pediatrics
Egléa Maria da Cunha Melo ${ }^{1}$

Ada Ávila Assunção 1

Roberto Assis Ferreira ${ }^{1}$

\section{Introdução}

\section{A estrutura do sistema de saúde e o cuidado ao paciente pediátrico}

Embora a mortalidade infantil pós-natal venha decrescendo no Brasil, ainda persiste em níveis acima do desejado. No país, morrem crianças por óbitos evitáveis atribuídos às condições sócioeconômicas das famílias e ao acesso e à qualidade da assistência à gestante e à criança 1,2,3,4 .

As doenças infecto-contagiosas, entre elas a pneumonia e a diarréia ligadas à desnutrição, são as principais causas de óbitos pós-natais 2 . Muitos óbitos aconteceram após a procura aos serviços de urgência por mais de uma vez com a mesma doença que ocasionou a morte $5 . \mathrm{Na}$ maioria dos casos, os óbitos podem ser evitados, se houver garantia de tratamento precoce. As políticas de saúde no mundo todo, incluindo a Prefeitura de Belo Horizonte, buscam organizar a atenção à saúde das crianças com ênfase no cuidado primário e nas medidas educativas 6 .

No entanto, as metas de descentralização e hierarquização no atendimento têm obtido êxito menor do que o esperado, pois persiste a alta demanda por atendimentos nos serviços de urgências 4,7,8. A superlotação freqüente dos serviços de urgências evidencia as dificuldades do sistema em atingir as metas de universalidade, igualdade e descentralização do acesso à atenção à saúde. Aos efeitos dos obstáculos para oferta 
de serviços, da fragilidade do sistema de referência e contra-referência e das precárias condições sócio-econômicas das crianças e de suas famílias, soma-se a precariedade dos recursos disponíveis nos serviços de saúde ${ }^{4,9}$, os quais, no conjunto, constituem desafios para alcançar a meta de "saúde para todos".

Os serviços de urgência do Sistema Único de Saúde (SUS) destinados às crianças gravemente enfermas são também freqüentados por crianças com doenças mais simples, e as famílias os utilizam como porta de entrada ao sistema 4,9,10, provocando elevada procura pelos serviços e interferindo no atendimento aos pacientes agudos, que são obrigados a enfrentarem as filas, embora cada serviço apresente um sistema de priorização mais ou menos eficiente.

Este estudo objetivou descrever fatores intervenientes no atendimento pediátrico, principalmente aqueles fatores ligados ao processo de trabalho em um serviço de urgências e à organização do sistema de saúde.

\section{Sujeitos e métodos}

A natureza do objeto justificou a abordagem qualitativa neste estudo de base empírica, utilizando-se de uma combinação de diferentes técnicas de investigação a fim de compreender o funcionamento e as situações de trabalho.

Foi estudado um ambulatório de urgências pertencente a um hospital público de pediatria. O serviço é formado por dois setores: (1) o ambulatório propriamente dito destinado ao fluxo de pacientes que são atendidos nos consultórios; (2) a unidade de observação. O corpo clínico é formado por 62 pediatras que trabalham em equipes. A maioria, 59\% (37), é composta por mulheres. Um número significativo de médicos, 44 (71\%), tem mais de 45 anos, sendo que $44 \%$ (27) estão no serviço há mais de 20 anos. A jornada atual do médico é de 12 horas, e eles praticam 12 horas extras semanais.

Participaram do estudo 44 médicos pediatras (70\% do universo). A idade dos sujeitos pesquisados variou de 30 a 66 anos, sendo que 30 médicos (68\%) encontravam-se na faixa de 45 e 55 anos, e 27 tinham mais de dez anos trabalhando no serviço. Dos sujeitos estudados, 25 eram mulheres, e 19, homens. Quanto ao tipo de vínculo, 31 eram efetivos, e 13 tinham vínculo temporário com a instituição.

O estudo foi aprovado pelo Comitê de Ética e Pesquisa da Universidade Federal de Minas Gerais e pelo Comitê de Ética do hospital. Os sujeitos estudados e a direção concordaram em participar e assinaram o Termo de Consentimento
Livre e Esclarecido. A seleção dos participantes ocorreu por livre adesão.

\section{As entrevistas coletivas}

Em 2003, foram entrevistados 44 médicos, abrangendo as sete equipes de plantão existentes. Cada entrevista realizada na sala de conforto médico durou trinta minutos. Elas foram guiadas pelos temas que surgiram na fase exploratória, caracterizada por observações abertas (sem roteiro prévio) e entrevistas simultâneas durante o atendimento dos pacientes pelos pediatras. Os temas diziam respeito às queixas de cansaço, à percepção do trabalho e seus reflexos sobre o humor do pediatra, às dificuldades e situações extremas vivenciadas durante o plantão. Procurouse fazer emergir possíveis associações entre os sentimentos referidos e as características gerais do trabalho, com ênfase nos aspectos organizacionais do serviço e do sistema de saúde.

\section{As observações do trabalho}

Entre os médicos entrevistados em 2003, sete foram observados no trabalho ainda naquele ano. Foram adotados os princípios teóricos e metodológicos da escola da ergonomia da atividade, a qual considera a distinção entre "o que" foi estabelecido para os trabalhadores executarem e "como" eles respondem às exigências do trabalho ${ }^{11}$.

Uma vez que a atividade não pode ser reduzida ao que se consegue observar, a etapa da autoconfrontação dos resultados das entrevistas e observações, estratégia que busca, na palavra livre do trabalhador, compreender os sentidos que ele próprio imprime aos resultados obtidos pelo pesquisador 12 , permitiu aceder aos aspectos não-objetiváveis do trabalho.

O risco de provocar alterações no comportamento dos indivíduos observados foi atenuado pela permanência prolongada da pesquisadora no campo, a qual procurou uma aproximação com os sujeitos a fim de apresentar os objetivos pretendidos e estabelecer elos de confiança, como propõem Assunção \& Lima 12 eVasconcelos 13 .

Cada uma das sessões de observação durou quatro horas. O pediatra foi acompanhado nas consultas, durante os deslocamentos até a enfermaria ou serviço social e na sala de conforto em momento de pausa entre um atendimento e outro, quando era possível.

Foram registradas as verbalizações dirigidas ao paciente e ao acompanhante, e vice-versa, e ao pesquisador (verbalização simultânea), na forma em que ocorreram, permitindo identificar comportamentos não-intencionais ou incons- 
cientes e explorar tópicos que os trabalhadores dificilmente apresentariam fora do contexto temporal-espacial da situação de trabalho, conforme salientam Assunção \& Lima 12.

\section{Pesquisa documental e dados quantitativos}

As informações sobre o histórico da instituição e a produção de consultas foram colhidas dos documentos e boletins estatísticos existentes nos arquivos do hospital. Os dados demográficos foram obtidos junto ao departamento de pessoal, que disponibilizou as fichas do seu arquivo.

Foram estudados os documentos elaborados pela direção no planejamento para 2004 e 2005, o relatório do Fórum de Discussão do Ambulatório de Urgência e Emergências, ocorrido em junho de 2003, e o relatório do Conselho Regional de Medicina. Informações complementares foram buscadas junto a funcionários de diferentes setores quando se fizeram necessárias.

Tomou-se o ano de 2004 como referência. Foram analisados os quadros existentes no boletim estatístico de 2004, que diziam respeito à idade dos pacientes atendidos e internados, tipo de atendimento, número de consultas por mês e no ano, procedência das crianças e nosologia prevalente.

O tempo de espera para consulta não estava disponível nos boletins do hospital, foram, então, tomados o mês de março e dezembro para levantamento dos dados diretamente nas fichas dos pacientes atendidos. Foram analisadas 517 $(4,6 \%)$ fichas de atendimento do mês de março, escolhidas aleatoriamente, e 310 (4,9\%) do mês de dezembro. Depois de reunidas as fichas, de acordo com o registro da hora de chegada do paciente ao hospital, foram selecionadas a primeira, a vigésima e, a seguir, os seus múltiplos. $\mathrm{O}$ material reunido permitiu confeccionar os dados que foram apresentados.

\section{Procedimentos de análise, tratamento e sistematização dos dados}

Os registros das verbalizações e dos comportamentos observados foram analisados buscando apreender as seguintes variáveis: conteúdo das entrevistas dirigidas pelo pediatra ao acompanhante, a abordagem da criança, a orientação final e o detalhamento da prescrição, os registros no prontuário, o conteúdo das comunicações com os outros atores presentes no plantão.

Os resultados preliminares das observações globais foram apresentados aos profissionais visando permitir a fala livre dos sujeitos e, assim, autoconfrontar as informações coletadas com a vivência subjetiva e confrontar o trabalho pres- crito com o trabalho real, seguindo o método de Guérin et al. ${ }^{11}$.

Numa etapa subseqüente, os resultados extraídos de uma primeira análise foram tratados a partir de uma segunda pauta de temas que sobressaíram da leitura flutuante dos discursos dos sujeitos e das verbalizações colhidas em situação e em autoconfrontação: (1) meios materiais necessários ao tratamento (leitos disponíveis, fluxo dos pacientes para outros serviços desejados); (2) demanda (aglomeração do serviço); (3) gravidade do caso; (4) conduta do acompanhante para com o médico.

\section{Resultados}

O paradoxo entre a missão do hospital, a demanda dos usuários e o julgamento do pediatra

No plano prescrito, aos médicos plantonistas cabe atender a demanda e assistir criança que chega ao serviço de urgência em estado grave até a sua estabilização, reavaliando e acompanhando as crianças em observação fora do leito e assistindo os casos semi-internados no período noturno. Em torno de $71 \%$ das internações no hospital estudado referem-se a crianças entre um mês e quatro anos, embora sejam atendidas todas as crianças até a idade de 12 anos. Paralelamente, cumpre-se também a função de formação dos acadêmicos de medicina.

Em 2004, foram realizadas 91.551 consultas, com uma média mensal de 7.629 consultas e média diária de 254 . O mês de julho contou com o menor número de atendimentos, e março, o mês com o maior número, sendo que, nesse mês, a média diária de consultas chegou a 371 (Figura 1).

O perfil da demanda atendida suscita discussão, pois, apesar da vocação do serviço em atender os casos agudos, quase a metade dos atendimentos, em todos os meses de 2004, diz respeito a procedimentos básicos que seriam destinados à atenção primária, pois são consultas simples, nas quais a criança é atendida e não necessita de nenhum procedimento ou medicação, retornando para casa. São atendidas crianças de Belo Horizonte e da região metropolitana.

Existe um paradoxo entre um serviço constantemente lotado, a julgar pela aglomeração de crianças e de seus acompanhantes na sala de espera, e o registro de 732 crianças em 2004, consideradas sadias pelo médico atendente; e de $50 \%$ de casos considerados como consultas simples (Figura 2), que, em tese, seriam demandas para o cuidado primário.

Tanto as estatísticas quanto os resultados das entrevistas denotam a heterogeneidade dos atendimentos, a qual não estaria coerente com 


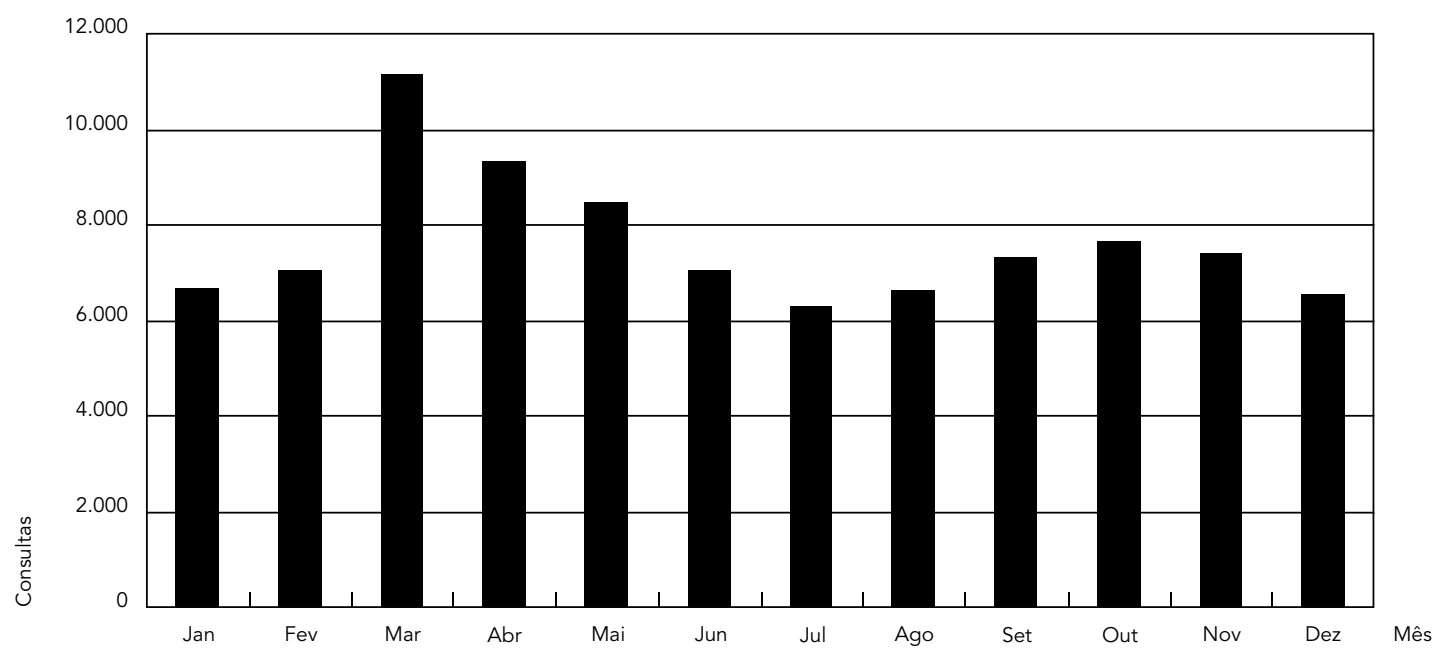

Figura 2

Distribuição das consultas simples e total de consultas de acordo com o mês, em 2004

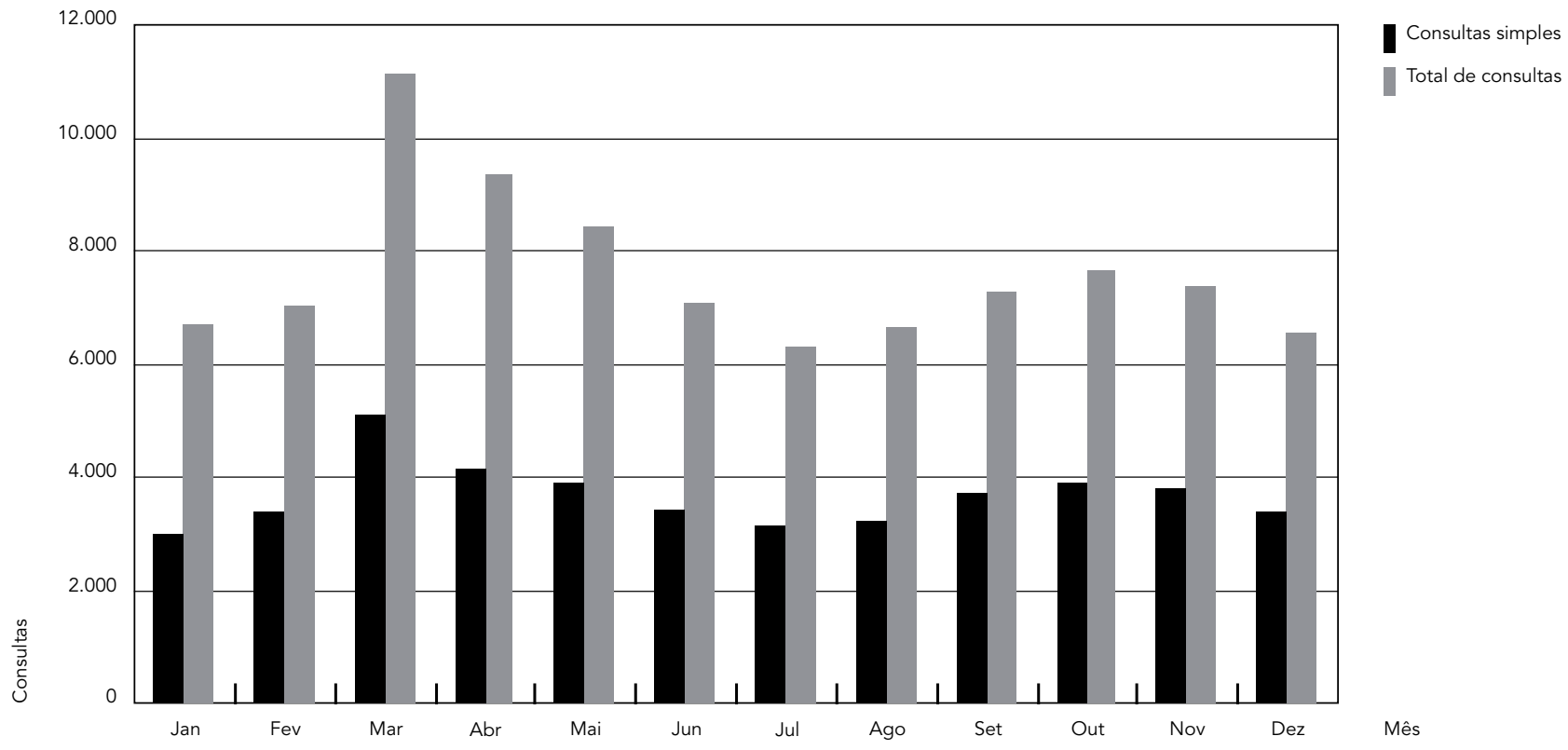


a vocação do serviço, que, no modelo vigente, foi idealizado como referência para casos agudos. O tipo de consultas atendidas revela a característica do serviço em atender casos agudos, conforme sua missão, mas também de acolher casos não urgentes. A importância em destacar essa característica deve-se ao volume excessivo de crianças aguardando por atendimento em determinadas épocas do ano com efeitos sobre a qualidade do atendimento que estaria ameaçada ao deixar aguardando, na fila, uma criança que deveria ser acolhida de imediato.

Por um outro lado, para a implantação da triagem classificatória de risco nos serviços tipo porta aberta, conforme recomendação do Ministério da Saúde 14, o hospital planeja adequação de área física, treinamentos e estratégias para vencer resistências, principalmente por parte dos médicos que afirmam ser arriscado devolver as crianças consideradas sem risco ao centro de saúde, uma vez que o atendimento, nesses locais, não será garantido para o mesmo dia ou para o dia seguinte. Alegam temer que alguma criança possa ter o quadro agravado nas 24 horas após a avaliação. Segundo eles, a possibilidade de isso acontecer diz respeito, principalmente, às crianças muito pequenas, às menores de um ano de idade.

Às crianças que vão demandar tempo em observação fora do leito e aos seus acompanhantes, é necessário garantir um mínimo de conforto e agilidade. Viu-se que o tempo de espera por resultados de exame é fator gerador de tensão principalmente para acompanhantes cansados e com longo tempo de permanência no serviço.

"Aqui tem um problema, a mãe que entra não sai até a conclusão porque eles têm medo dela fugir sem uma solução para o caso e dar algum problema. Às vezes a gente pede exame e demora seis horas, eu fico transtornada porque acho que a mãe teria direito de sair e voltar (...) Não tem o que comer, isso me causa estresse. Tenho dó da mãe" (Pediatra 12, entrevista).

No estudo, o volume de atendimentos parece estar ligado à insatisfação dos médicos com o trabalho, esses relataram perceber prejuízo na qualidade do atendimento quando a demanda aumenta:

“A gente, no final da tarde, início da noite, já não raciocina muito bem (...) tenho muito medo de deixar passar alguma coisa que não dei conta de ver. Já vi menino internar, o pessoal examina e não percebe a pneumonia na hora, um tempo depois o outro médico vem examina e faz o diagnóstico" (Pediatra 7, entrevista).

Os dados obtidos permitem explicar a grande demanda pelo serviço em cinco grupos de determinantes: sazonalidade do perfil epidemiológico, fatores ligados à fragilidade do sistema de referência e contra-referência, especificidade do serviço, fatores ligados à conduta do pediatra $\mathrm{e}$ fatores ligados aos usuários, os quais serão apresentados a seguir.

\section{- Fatores epidemiológicos}

A superlotação é sazonal e, no caso estudado, acontece nos meses de março a junho quando ocorre maior prevalência de crises respiratórias na população-alvo, que exigem observação por algumas horas, principalmente os casos de asma e broncoespasmo, que totalizaram 15.637 (17\%) crianças atendidas em 2004. Essa observação é feita fora do leito, sendo que o hospital não tem uma área específica para essas crianças, as quais ficam nos corredores aumentando o fluxo de acompanhantes e crianças, criando um clima propício à irritabilidade dos profissionais e de acompanhantes.

\section{- A fragilidade do sistema de referência e contra-referência}

Segundo as definições da gestão, os casos oncológicos e cirúrgicos devem ser encaminhados para serviços específicos. Em realidade, o fluxo é difícil, o que piora nos períodos de pico, dada a escassez de leitos nos hospitais contratados pelo SUS e a recusa dos hospitais privados em aceitar casos complexos: "existe uma animosidade, ninguém tem disponibilidade para receber os nossos pacientes" (Pediatra 10, entrevista).

Os casos cirúrgicos também geram angústia, quando não foi possível garantir o encaminhamento da criança atendida. Um médico que estava deixando o plantão pela manhã desabafa: “Não dormi nada no meu horário de descanso porque fiquei preocupado com o menino do leito um da semi-internação, que é uma criança com apendicite, não consegui transferir para cirurgia. Informaram que o médico do outro hospital tem que dar a vaga, mas ele fala para não mandar porque eles estão lotados" (Pediatra 8, entrevista).

Os pediatras recebem as crianças de outros serviços e informam que não tentam transferir crianças com quadros neurológicos, por exemplo, paralisia cerebral, mesmo se o hospital estiver lotado, porque já sabem: os outros hospitais não aceitam.

Casos mais complexos ou que vão demandar um tempo maior de internação não são aceitos pelos outros serviços. Uma médica adverte o pessoal da portaria responsável pela internação após solicitar vaga para internar uma criança de três meses com bronquiolite: "Não adianta vocês pedirem vaga para ela na central da prefeitura, podem deixar aqui no hospital, porque eles vão 
perguntar a idade e o diagnóstico e vão negar. Eles sabem que uma bronquiolite em uma criança tão pequena pode complicar. Eu poderia falar que o diagnóstico é asma e aí eles aceitam, mas não vou fazer isso porque sei que eles vão devolver a criança" (Pediatra 10, observação direta).

\section{- Características do serviço}

Além dos fatores epidemiológicos, contribuem para o fenômeno algumas características da estrutura do hospital. Como dito anteriormente, o acesso livre e aberto ao serviço viabiliza a chegada concomitante de crianças em estado grave e crianças com problemas pertinentes aos cuidados do tipo primário.

A tentativa de implantar um sistema de triagem não obteve sucesso, pois, segundo os pediatras, é difícil ter segurança em encaminhar para o centro de saúde mesmo aquela criança cujo quadro, ao primeiro atendimento, não evidenciou uma urgência.

A insegurança quanto à qualidade da assistência prestada no nível básico da atenção, como se vê em: "as mães contam que trazem os filhos aqui porque o médico do Programa Saúde da Família não entende muito de criança" (Pediatra 10, observação do trabalho), explicaria o afluxo de pacientes ao serviço de urgências. Tanto as mães quanto os próprios médicos sentem-se inseguros de encaminhar as crianças para a atenção básica, pois reproduzem a cultura que procura por um atendimento com densidade tecnológica ou suspeitam da demora e da inconsistência do atendimento praticado por profissionais que não são pediatras: na hora da urgência, a mãe corre para o local que ela sabe que resolve.

A definição do que é urgência em pediatria é um tema em aberto, porque os motivos que levam os acompanhantes das crianças a procurarem os serviços de urgência são muito variados e dependem da ansiedade dos pais, da experiência anterior com alguma perda, das facilidades de locomoção, da recusa em aceitar o médico de família para o atendimento das crianças: "Eu trago aqui porque sei que vai ser feito a medicação, ela vai ser reavaliada, se precisar vai fazer RX. Quando levo no posto, além de ter que esperar, eles não resolvem. Agora mesmo, cheguei aqui às quatro horas, ela fez nebulização, três vezes, fez RX e está bem melhor. São nove horas e já vou voltar para casa" (verbalização da mãe durante a observação da consulta).

A localização do hospital, no cruzamento de vias de circulação dos ônibus vindos de quase toda a cidade e região metropolitana, também conta no afluxo de pacientes, que, em outras cidades da região, têm mais facilidade para se di- rigirem à capital do que no centro de saúde de seu distrito.

\section{- Fatores ligados à tomada de decisão do pediatra}

Como relatado acima, o pediatra não segue sem julgamento algumas regras do serviço e do sistema de saúde no tocante ao modelo de descentralização e hierarquização do cuidado e, em vez de encaminhar os casos que teoricamente deveriam ser atendidos em outros serviços, deixam as crianças com quadros clínicos mais graves internados no próprio hospital, e, no período de alta demanda, quando não há leito para internação ou ambulância disponível, é freqüente a criança ficar aguardando na maca em um corredor do serviço, hipersolicitando a vigilância dos pediatras.

Conta, também, na decisão do pediatra em internar ou não a criança, a sua avaliação sobre as condições sócio-econômicas e culturais da mãe para implementar o cuidado necessário: "quando desconfio que a mãe não vai cuidar bem, não mando para casa em hipótese alguma" (Pediatra 19, observação do trabalho).

A evolução de um quadro estável para uma crise grave pode se dar muito rapidamente. Sabendo disso e diante da incerteza da garantia do atendimento no centro de saúde próximo à moradia do paciente: "fico inseguro para dar alta, quando imagino como é a casa dessas crianças, o menino ainda chiando, penso vai chegar lá e voltar em poucas horas" (Pediatra 23, entrevista). "Sei lá se ele passa mal à noite e a mãe não tem para onde correr (...) se ele piorar de repente e a mãe não tiver como trazer" (Pediatra 2, observação do trabalho).

\section{O volume de atendimentos perturba os tempos necessários ao ato pediátrico}

No tocante ao trabalho que os pediatras desenvolvem no contexto descrito, é justo avaliar a discrepância entre o número oficial de consultas produzidas e o número praticado. Quando a equipe está completa, são chamadas, para atendimento, de 21 a 24 crianças por hora, sendo três a quatro para cada médico no período do estudo. Essa taxa, mesmo sendo aceita como adequada, não reflete a carga de trabalho, pois o atendimento a uma criança pode necessitar de mais tempo ou consultas subseqüentes, enquanto ela aguarda observação fora do leito, além de inúmeros procedimentos a depender do seu estado, criando gargalos nos outros atendimentos. As crianças com broncoespasmo podem necessitar de duas a três reavaliações para permitir ao médico decidir sobre a internação ou alta. 
É freqüente a mobilização de dois ou mais médicos na unidade de observação visando ao cuidado às crianças muito graves. Nesses casos, haverá acúmulo na fila de espera pelo atendimento. Se há demora na estabilização da criança, os médicos mobilizados pela criança em estado grave não atendem consultas em um ou dois horários, ocasionando diminuição na quantidade de profissionais para o atendimento da demanda. Como o número de atendimentos por hora depende do número de médicos na equipe, os colegas, às vezes, redistribuem os pacientes destinados ao médico que está ajudando no atendimento da emergência.

\section{O tempo de espera pelo atendimento}

O tempo de espera pelo atendimento pode variar muito, relacionando-se estreitamente com a demanda quantitativa e qualitativa das consultadas efetivadas. Viu-se que, nos períodos de alta demanda, um paciente pode esperar até sete horas (Figura 3), gerando um quadro de angústia, desconforto e irritabilidade nos usuários, cuja face mais visível é a freqüência de agressões físicas e verbais e processos contra erros médicos.
O tempo de espera é proporcional ao número de crianças que procuram o serviço. No mês de março de 2004, o mês de maior demanda no ano, $27,3 \%$ dos pacientes esperaram de $1 \mathrm{~h} 01$ a 2 horas para o início da consulta; em dezembro, a porcentagem de pacientes foi de 22,3\%. Em março, $20 \%$ dos pacientes esperaram de $2 \mathrm{~h} 01$ a 3 horas; sendo que, em dezembro, a porcentagem de espera, nessa faixa, foi de $10 \%$. Viu-se, ainda, que $15,7 \%$ dos pacientes em março e apenas $1 \%$ em dezembro esperaram de $3 \mathrm{~h} 01$ a 4 horas aguardando o atendimento. Mais de $11 \%$ dos pacientes atendidos, em março, esperaram mais de 4 horas para serem atendidos, sendo que, em dezembro, essa porcentagem cai para $0,3 \%$ (Figura 3 ).

O serviço de urgência do hospital tem suas regras para priorização das crianças que chegam à procura de assistência. As crianças encaminhadas de outros serviços ou aquelas que, durante a espera, esboçaram sinais de gravidade percebidos pelo pessoal da portaria ou pelos acompanhantes têm prioridade no atendimento. Essa conduta do serviço é bastante delicada nos dias atuais, pois, diante das declarações de saúde para todos e igualdade de acesso, torna-se inaceitável a espera prolongada, e os acompanhantes des-

Distribuição percentual das consultas realizadas em um serviço de urgências pediátricas, em março e em dezembro de 2004, de acordo com o tempo de espera entre a chegada ao hospital e o início da consulta.

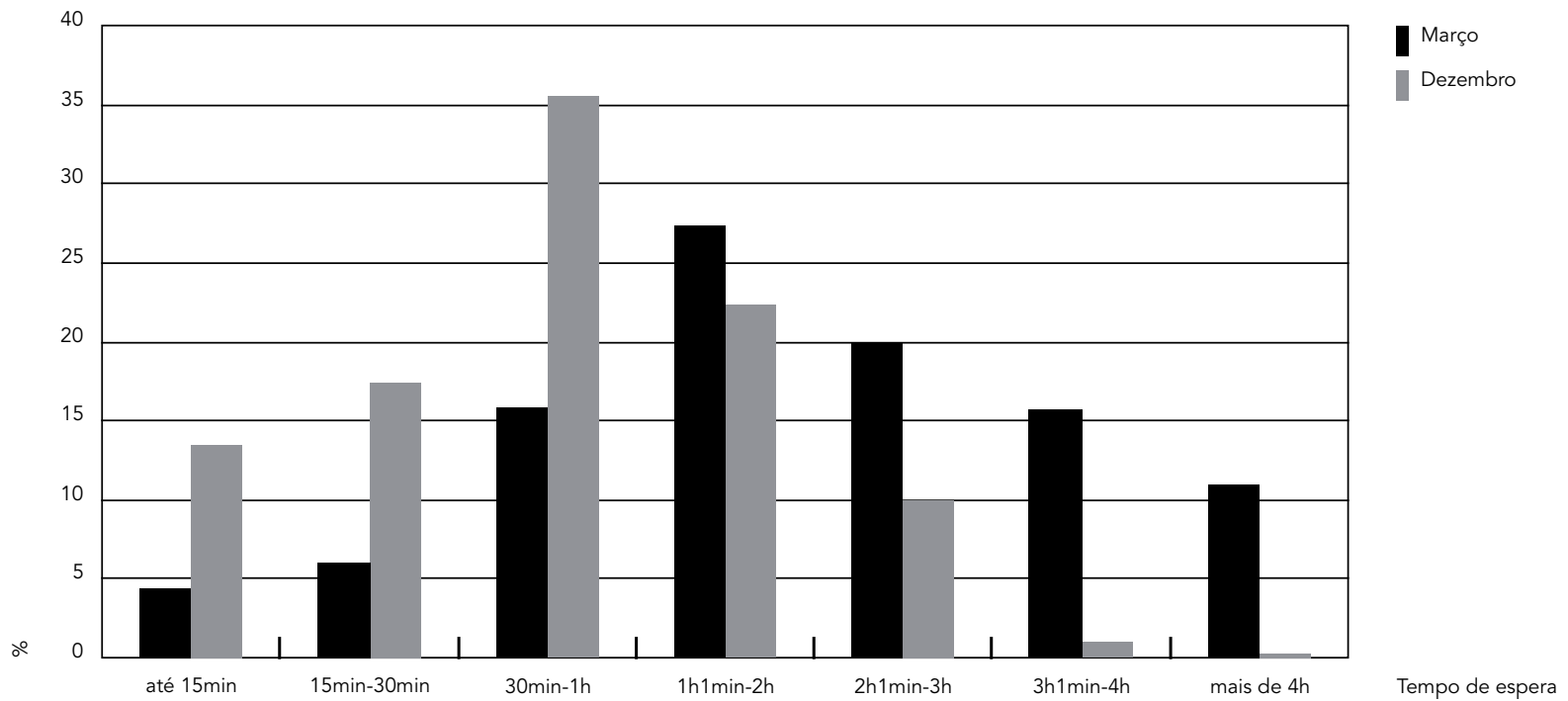


contentes tornam-se, por vezes, violentos quando percebem que outra criança teve prioridade no atendimento.

A espera pelo resultado de exames solicitados é um fator que, segundo os médicos, contribui para o prolongamento da permanência da criança no hospital e aumenta a irritabilidade dos seus acompanhantes.

\section{Escutar, decidir e orientar sob} pressão temporal

Outro componente da atividade do pediatra em plantões de urgência, o qual poderia explicar o cansaço relatado pelos sujeitos, é a necessidade de tomar decisões rápidas e, ao mesmo tempo, colher informações essenciais para o seu raciocínio em um curto espaço de tempo, o que exige dele capacidade de fazer as perguntas certas e dirigir a entrevista com o acompanhante para obter os dados objetivos. As intervenções rápidas são necessárias, por exemplo, para os casos de choque hipovolêmico ou séptico e insuficiência respiratória grave e suas repercussões.

Por outro lado, chegam crianças cujos acompanhantes necessitam de orientações detalhadas, as quais solicitam estratégias educativas essenciais para a resolubilidade dos casos, como mudança de dieta ou um caso simples de virose, por exemplo. Assim, o contato com os acompanhantes das crianças exige disponibilidade dos pediatras. Tome-se como exemplo o extrato de uma verbalização do pediatra: "sabe, mãe, isto é uma virose, a febre dura de três a quatro dias. Você deve evitar dar muito remédio. Pode ser que tenha diarréia, aí você deve dar soro. Se a criança estiver bem, é só dar remédio para febre e muito líquido, pode ser chazinho" (Pediatra 10, observação do trabalho).

Os tempos do serviço são imperfeitos para escutar a mãe. Evidencia-se um conflito entre o tempo para o pediatra agir e o tempo para a mãe compreender o que está sendo solicitado. O médico necessita dar conta de administrar variáveis que podem interferir na qualidade do atendimento: "é preciso estar calmo, se você apavora, o acompanhante pode se descontrolar e necessitar acompanhamento de profissionais, como psicólogo, que o serviço não disponibiliza" (Pediatra 16, entrevista).

As mães, quando estão se sentindo culpadas, têm necessidade de justificar o seu comportamento no curso do adoecimento do seu filho. Uma criança que chega com um grau de dificuldade respiratória importante, ao médico, interessa, principalmente, saber o tipo e o horário que o medicamento foi ministrado e a duração daquele quadro. As respostas a essas perguntas nem sempre virão na clareza e velocidade necessárias para o raciocínio e tomada de decisão do pediatra, pois a mãe precisa explicar que expôs a criança ao relento na noite anterior, apesar de ter garantido um bom agasalho: "quando vejo uma mãe gritando, faço esforço para não achar que é histeria e que a criança de fato está grave, mas sei que, muitas vezes, tem algo por trás do grito, sendo a culpa fator muito presente" (Pediatra 24, entrevista).

Os casos especiais solicitam capacidade em escutar, decidir e agir. Muitas vezes, o acompanhante não entende as perguntas feitas, e eles têm que explicar novamente. Esse ato torna-se complexo, uma vez que a mãe precisa de tempo para expressar as suas angústias, justificar o seu comportamento e assimilar uma orientação: "eu pergunto uma coisa, e a mãe me responde outra completamente diferente, não sei se não ouviu ou se não entendeu, é preciso muita paciência" (Pediatra 25, observação do trabalho).

\section{Discussão}

Os autores 14,15,16 identificam a eficácia das unidades de observação nos serviços de atendimento a crianças agudamente enfermas, sugerindo que tais unidades aumentem a qualidade do cuidado prestado às crianças. As unidades de observação podem reduzir os prejuízos provocados pelo ato de mandar para casa uma criança com um distúrbio sério. No entanto, no ambulatório estudado, a organização do serviço não acomoda as necessidades da unidade de observação, por exemplo, o seu efetivo, gerando gargalo no fluxo de atendimento às consultas, quando um médico se desloca do ambulatório para ajudar o colega que está na unidade de observação.

Os médicos estudados ressentem-se de assistir crianças que deveriam estar sendo atendidas no cuidado primário, expressando uma preocupação com as crianças mais graves que também chegam necessitando de um cuidado que não está disponível em outros níveis do sistema. Por um lado, os profissionais estudados demonstram um esforço em atender a quem chega, seguindo o princípio do sistema de garantir o acesso. Por outro lado, eles reconhecem as necessidades das crianças em estado grave que solicitam maior tempo de atendimento, muitas vezes, em equipe.

Kovacs et al. 4 salientam o prejuízo na qualidade do atendimento prestado na urgência para onde se dirigem, ao mesmo tempo, casos que necessitam de atendimento imediato e casos mais simples que poderiam esperar. Os autores explicam que os pacientes que necessitam de atendi- 
mento rápido vão esperar, e aqueles que demandam cuidado primário, por exemplo, orientação geral, terão atendimentos pontuais restritos às queixas, o que comprometerá a integralidade da assistência. A procura do serviço de urgência foi atribuída à densidade tecnológica dos serviços, o que evidencia a necessidade de tecnologia que permita a resolução da maioria dos casos como disponibilidade para raio $\mathrm{X}$, urina rotina, exames de sangue mais solicitados etc.

O Royal College of Paediatrics and Child Health 17, após uma revisão sobre o cuidado das crianças na comunidade, no Reino Unido, lançou um documento no qual sugere um modelo de oferta de serviços com acesso rápido para as crianças que necessitam de cuidados urgentes. Craft ${ }^{8}$ comenta o documento e antevê, no Reino Unido, cada localidade tendo uma unidade de observação, funcionando durante o dia, mas sem pacientes internados no período noturno.

Convém, no entanto, lembrar que existe uma contradição dessas propostas com as necessidades de internação. Zebrack et al. 15 estudaram uma unidade de observação pediátrica em um hospital nos Estados Unidos. Os autores mostraram que os pacientes em observação internam mais à tarde e começo da noite, o que foi confirmado pelos médicos pesquisados neste estudo.

Kovacs et al. ${ }^{4}$ procuraram conhecer o tipo de acesso às ações básicas de saúde que o grupo de crianças atendidas em cinco serviços de urgência tinham na rede de saúde de Recife e concluíram que a hierarquização não depende dos desejos dos técnicos, mas da possibilidade de o sistema conhecer as características dos atendimentos e dos usuários.

Nas portas de entrada do sistema de saúde que atendem urgência, a triagem classificatória de risco tem sido implementada, recomendada pelo Ministério da Saúde do Brasil 18, principalmente no atendimento ao adulto, no entanto, nos serviços que atendem pediatria, a implantação tem sido realizada com mais cuidado, provavelmente levando-se em conta, entre outros fatores, como aqueles alegados pelos pediatras estudados, por exemplo, a dificuldade de estabelecer o que é urgência em pediatria e a fragilidade das crianças muito pequenas.

Os resultados das pesquisas orientam uma interlocução entre os serviços que atendem à comunidade e aqueles organizados para o atendimento aos casos agudos. Reading et al. 19 organizaram grupos focais com pediatras do cuidado primário para entender a dificuldade em recrutar pediatras para trabalhar na comunidade e concluíram que a ruptura existente entre cuidado primário e os serviços de atendimento ao agudo só será resolvida quando os treinamentos capa- citarem os pediatras para o atendimento, tanto no cuidado primário quanto para os serviços de atendimento do agudo.

Zebrac et al. ${ }^{15}$, examinando os registros dos pacientes admitidos, na unidade, de agosto de 1999 a julho de 2001, encontraram um aumento de crianças que necessitam de observação no inverno e uma demanda elevada por internações nesse período. Tanto no estudo dos autores como na presente pesquisa, o número de crianças com quadro simples de virose é elevado. $\mathrm{O}$ cuidado a essas crianças demanda disponibilidade do médico, pois, mesmo sendo de resolução simples, demanda orientações detalhadas, conforme evidenciado nas observações realizadas do trabalho médico. Essa característica é associada a sentimentos negativos pelos estudos já realizados. Por exemplo, Grieves 20, ao procurar identificar causas de desânimo entre os médicos generalistas no Reino Unido, encontrou que $46 \%$ dos médicos estavam frustrados com as consultas consideradas triviais, as quais são fonte de desencanto dos médicos com a profissão. $\mathrm{Na}$ amostra estudada, não foi possível explorar esse tipo de sentimento, o que deverá suscitar investigações futuras.

O tempo de espera para consulta mostrou ser fonte de tensão. Magalhães et al. ${ }^{9}$ mostraram que, quando o cliente decide procurar o serviço de emergência, já chega com a idéia da necessidade de um atendimento rápido e qualquer espera pode trazer muita angústia.

Franco ${ }^{21}$, estudando o processo de decisão dos médicos que atendiam em centro de saúde da rede municipal de Campinas, colocou em evidência que, se o processo de atenção à criança for colocado em posição central na organização do serviço, haverá uma melhora na qualidade do cuidado prestado. Os fatores que são levados em conta na tomada de decisão dos pediatras na urgência ultrapassam a competência técnica. A rede de fatores implicada na decisão necessita de melhor compreensão.

A qualidade da atenção à saúde pode ser avaliada nas suas dimensões objetivas, as quais se referem ao mensurável, portanto, com força de generalização, por exemplo, duração da espera e número de atendimentos, sendo ambos indicadores de custo-benefício na assistência à saúde. Contudo, as dimensões subjetivas também fazem parte das propostas de avaliação da qualidade em saúde. A abordagem metodológica adotada neste estudo mostrou-se adequada para os objetivos traçados e poderá ser utilizada em futuras investigações visando aprofundar o conhecimento sobre as dimensões subjetivas e objetivas do trabalho.

Uma estratégia de gestão dos sistemas de saúde centrada nas dificuldades vivenciadas pe- 
los trabalhadores em saúde pode abrir vias para a elaboração de políticas menos superficiais, visando garantir o acesso e a qualidade dos serviços. Sob esse prisma, os resultados sugerem incorporar parâmetros como a subjetividade na administração dos recursos humanos dos sis- temas de saúde, visto que, no desenvolvimento do trabalho, a dimensão técnica de como e por que fazer articula-se a componentes subjetivos de percepção, afeto e esforço em contornar as dificuldades determinadas por fatores extrínsecos à atividade.

\section{Resumo}

Este estudo qualitativo de base empírica apresenta as condições materiais e organizacionais do trabalho dos pediatras em um serviço público de urgências pediátricas, com vistas a identificar fatores que estejam interferindo no atendimento. Realizou-se um estudo do trabalho por meio de entrevistas coletivas e observações diretas da atividade. Os resultados foram tratados de maneira articulada aos dados estatísticos $e$ históricos obtidos de uma pesquisa documental. Foram entrevistados 44 médicos pertencentes a sete equipes de pediatras, entre os quais, sete pediatras foram observados em situação real de trabalho, buscando analisar a atividade realizada. Viu-se que a fragilidade do sistema de referência e contra-referência é fator determinante do volume de atendimentos. O ambiente marcado pela aglomeração de pacientes gera pressão temporal com interferências diretas sobre o ato pediátrico praticado. Os autores identificaram as estratégias informais construídas e implementadas pelos sujeitos visando garantir a qualidade do atendimento segundo os preceitos da pediatria.

Serviços Médicos de Emergência; Serviços de Saúde; Pediatria

\section{Colaboradores}

Todos os autores participaram da elaboração, redação e revisão final do artigo. 


\section{Referências}

1. Szwarcwald CL, Leal MC, Jourdan AMF. Mortalidade infantil: o custo social do desenvolvimento brasileiro. In: Leal MC, Sabrosa PC, Rodrigues RH, Buss PM, organizadores. Saúde ambiente e desenvolvimento. São Paulo: Editora Hucitec/Rio de Janeiro: ABRASCO; 1992. p. 251-78.

2. França E, Souza JM, Guimarães MDC, Goulart EMA, Colosimo E, Antunes CMF. Associação entre fatores socioeconômicos e mortalidade infantil por diarréia, pneumonia e desnutrição em região metropolitana do Sudeste do Brasil: um estudo caso-controle. Cad Saúde Pública 2001; 17:1437-47.

3. Goulart LMHF, Somorriba MG, Xavier CC. A percepção das mães sobre o óbito infantil: uma investigação além dos números. Cad Saúde Pública 2005; $21: 715-23$.

4. Kovacs MH, Feliciano KVO, Sarinho SW, Veras AACA. Acessibilidade às ações básicas entre crianças atendidas em serviço de pronto-socorro. J Pediatr (Rio J) 2005; 81:251-8.

5. Hadad S, França E, Uchôa E. Mortes infantis por causas evitáveis e qualidade dos serviços de saúde: um estudo da percepção materna da doença e do atendimento à criança doente. Cad Saúde Pública 2002; 18:1519-27.

6. Katz M, Rubino A, Collier J, Rosen J, Ehrich JHH. Demography of pediatric primary care in Europe: delivery of care and training. Pediatrics 2002; 109:788-96

7. Cecílio LCO. As necessidades de saúde como conceito estruturante na luta pela integralidade e eqüidade na atenção em saúde. In: Pinheiro R, Mattos RA, organizadores. Os sentidos da integralidade na atenção e no cuidado à saúde. Rio de Janeiro: Instituto de Medicina Social, Universidade do Estado do Rio de Janeiro/ABRASCO; 2001. p. 113-26.

8. Craft A. Out of hours care. Arch Dis Child 2004; 89:112-3.

9. Magalhães AMM, Paskulin LMG, Martins NGR, Silva SC. Implantação de um sistema de triagem em unidades de emergência. Revista HCPA 1989; 9:182-7.

10. Luo X, Liu G, Frush K, Hey LA. Children's health insurance status and emergency department utilization in the United States. Pediatrics 2003; 112: 314-9.
11. Guérin F, Laville A, Daniellou F, Duraffourg J, Kerguelen A. Compreender o trabalho para transformá-lo - a prática da ergonomia. São Paulo: Editora Edgard Blucher; 2001.

12. Assunção AA, Lima FPA. A contribuição da ergonomia para a identificação, redução e eliminação da nocividade do trabalho. In: Mendes R, organizador. Patologia do trabalho. 2a Ed. Rio de Janeiro: Editora Atheneu; 2003. p. 1767-89.

13. Vasconcelos EM. Complexidade e pesquisa interdisciplinar: epistemologia e metodologia operativa. Petrópolis: Editora Vozes; 2002.

14. Rentz AC, Kadish HA, Nelson DS. Physician satisfaction with a pediatric observation unit administered by pediatric emergency medicine physicians. Pediatr Emerg Care 2004; 20:430-2.

15. Zebrack M, Kadish H, Nelson D. Uma unidade pediátrica de observação híbrida: uma análise de 6.477 pacientes. Pediatrics 2005, 115:535-42.

16. American College of Emergency Physicians. Management of observation units, 1994. http://www. acep.org/webportal (acessado em Jun/2006).

17. Royal College of Paediatrics and Child Health. Strengthening the care of children in the community. London: Royal College of Paediatrics and Child Health; 2002.

18. Ministério da Saúde. Política Nacional de Atenção às Urgências. Brasília: Ministério da Saúde; 2004. (Série E - Legislação de Saúde).

19. Reading R, Surridge H, Steel S, Sansome A. The recruitment and training crisis in community paediatrics: what do registrars think? Child Care Health Dev 2002; 28:289-94.

20. Grieves S. Measuring morale - does practice area deprivation affect doctors' well-being? Br J Gen Pract 1997; 47:547-52.

21. Franco SC. A qualidade possível: o pediatra e o processo de decisão médica nos serviços públicos de saúde [Tese de Doutorado]. Campinas: Faculdade de Medicina, Universidade Estadual de Campinas; 2001.

Recebido em 07/Jun/2006

Versão final reapresentada em $05 / \mathrm{Fev} / 2007$ Aprovado em 23/Mai/2007 